\title{
Outbreak of Escherichia coli O157 in a nursery: lessons for prevention
}

\author{
L Al-Jader, R L Salmon, A M Walker, H M Williams, G A Willshaw, T Cheasty
}

\begin{abstract}
Objectives-To identify risk factors for transmission of verocytotoxin producing Escherichia coli O157 (VTECO157) and means of prevention.

Study design-Outbreak investigation: retrospective cohort study.

Setting-A nursery (child care centre) in North Wales.

Subjects-Children attending $(\mathrm{n}=104)$.

Methods-Faeces were examined using sorbitol MacConkey agar (SMAC), with cefixime, tellurite, and rhamnose; enrichment in modified tryptone soya broth; and immunomagnetic separation. Symptoms and exposure data were obtained from questionnaires to parents/guardians and children's toiletting and feeding records kept at the nursery.

Main outcome measure-A "case" was defined as a child with verocytotoxin producing $E$ coli $\mathrm{O} 157$ isolated from faeces, or a history of haemolytic uraemic syndrome (HUS) and antibodies to $E$ coli 0157 lipopolysaccharide, during the period 10 August to 30 September 1995.
\end{abstract}

Results-The attack rate was 31 in 104 . Two children developed HUS. There were higher attack rates among girls and friends who played together. Cases were more likely to attend the nursery more frequently. The mean number of recorded bowel motions/child/half day was 0.51 in cases and 0.21 in well children. Child to staff ratios were high preceding and during the outbreak.

PHLS Communicable Disease Surveillance Centre (Wales), Abton House, Wedal Road, Cardiff CF4 3QX, UK L Al-Jader

R L Salmon

Bangor Public Health Laboratory, Ysbyty, Gwynedd, Bangor

LL57 2PW, UK

A $M$ Walker

H M Williams

Laboratory of Enteric Pathogens, Central Public Health

Laboratory, Colindale, London NW9 5HT, UK G A Willshaw

$\mathrm{T}$ Cheasty

Correspondence to: Dr Salmon.

Accepted 15 February 1999 outbreak. This simple record could be considered by other child care facilities as a means of giving early warning of problems with infectious intestinal diseases.

(Arch Dis Child 1999;81:60-63)

Keywords: verocytotoxin producing Escherichia coli O157; transmission; children's nurseries; risks; infection control

Verocytotoxin producing strains of Escherichia coli, in particular serotype O157 (VTECO157), cause a wide range of illnesses from mild diarrhoea to haemorrhagic colitis with severe abdominal pain and bloody diarrhoea. ${ }^{1}$ About a quarter of diagnosed cases are admitted to hospital ${ }^{2}$ and between $2 \%$ and $7 \%$ of cases develop haemolytic uraemic syndrome (HUS), ${ }^{3}$ a form of renal failure with a case fatality rate of $3-17 \% .{ }^{4}$ In a substantial proportion of survivors of HUS, there is long term residual impairment of renal function. ${ }^{6}$ The highest incidence of diagnosed VTECO157 is in children under 5 years of age and HUS is a more likely complication in young children. ${ }^{2}$ Thus, although much recent interest in the UK has focused on the role of meat, ${ }^{7}$ even limited person to person transmission in the daycare environment can pose a serious public health threat. Such transmission does occur, ${ }^{89}$ as do outbreaks affecting children's daycare facilities, ${ }^{810} 11$ which are a well known risk factor for transmission of enteric pathogens. $^{12-15}$

The outbreak

VTECO157 was isolated from two men, aged 49 and 34, on 25 and 26 August 1995 by Bangor Public Health Laboratory (PHL). Both had diarrhoea with onsets on 18 and 22 August, respectively. Initial inquiries could not link these two patients. A third patient, a woman aged 52, with onset on 18 August, who lived elsewhere and had visited the area on 17 August, had VTECO157 isolated by Rhyl PHL on 25 August. A fourth patient, a local woman aged 38, with haemorrhagic colitis, had VTECO157 isolated on 31 August. On 1 September a 2 year old girl was reported to the local Environmental Health Department (EHD) who had been admitted to hospital in Liverpool on 21 August with HUS. This child attended a private nursery in the area. Two further cases of VTECO157 were confirmed that day by Bangor PHL in two girls, aged 1 and 3, attending the same nursery. A number of children in the nursery were reported as having severe diarrhoea and all subsequent cases were connected with it.

\section{The nursery}

This nursery occupied a large converted house, which was run by two proprietors and 12 staff. The nursery catered for a total of 104 infants and preschool age children who were divided into two main age groups, each occupying one of the two main floors. Unusually, the nursery kept particularly detailed records, not only of registration and attendance, but also of daily activity, to monitor educational and social development. For the younger children on the ground floor, a record of toiletting was also kept. 


\section{Methods}

EPIDEMIOLOGICAL

We undertook a retrospective cohort study of children attending the nursery to identify risk factors for the transmission of the disease.

A "case" was defined as a child with verocytotoxin producing $E$ coli O157 (VTECO157) isolated from faeces or history of HUS and antibodies to $E$ coli $\mathrm{O} 157$ lipopolysaccharide during the period 10 August to 30 September 1995 (eight days before the onset of the first case up until all the primary and secondary cases were identified as related to this outbreak).

All cases were interviewed initially by local public heath agencies. Parents of all children at the nursery were subsequently contacted to establish whether the children had had any symptoms and, if so, the onset date.

We carried out a detailed inspection of the nursery premises and sought detailed information from the staff. We obtained nursery records for the period 9 August to 5 September (when all the children were excluded from the nursery pending microbiological clearance). The demographic details of each child, the laboratory results, days attended, whether he/she ate in the nursery, the number of bowel motions recorded in the toilet book, and comments on activities were entered on a structured pro forma. A member of the nursery staff was asked to identify particular friends with whom each child played.

We carried out statistical analysis using Epi Info version $6 .{ }^{16}$ We compared categorical variables and trends using the $\chi^{2}$ test. We used the Mantel-Haenszel test for stratified analyses. We used relative risk (RR), plus/minus $95 \%$ confidence intervals (CI) for risk estimation. We compared continuous variables using the Mann-Whitney test.

\section{MICROBIOLOGY}

Two faecal samples separated by at least 48 hours were collected from each child attending the nursery. Most of these were collected as part of the screening programme which began on 5 September 1995. On the day of collection, samples were inoculated on to sorbitol MacConkey agar (SMAC), SMAC with cefixime, tellurite, and rhamnose, and into modified tryptone soya broth. ${ }^{17}$

After storage at $4^{\circ} \mathrm{C}$, we re-examined samples by enrichment culture in broth followed by immunomagnetic separation using magnetic beads coated with antibody to $E$ coli $\mathrm{O} 157$ (Dynabeads anti-E coli; Dynal, Wirral, UK), ${ }^{18}$ and by culture on SMAC and SMAC with cefixime and tellurite.

Characterisation of isolates was carried out by phage typing, resistance typing, verocytotoxin (VT) typing, and DNA based methods. ${ }^{19}$

\section{Results}

DESCRIPTIVE

The 104 children ( 65 boys, 39 girls), included six unregistered children of staff. Median age was 4 years (range, 4 months to 7 years). During the 19 day period of inquiry, when the nursery was open, the median number of chil-

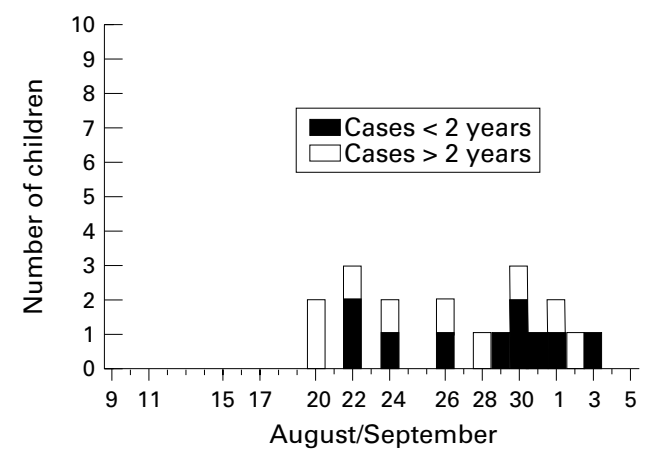

Figure 1 Epidemic curve showing the date of onset of symptomatic cases.

dren attending the nursery each day was 39 (range, 28-52). It was a holiday season, with children who were marked as on holiday in the register, median 2.5 (range $0-9$ ). There were an additional three cases among the nursery staff and 13 secondary cases (seven adults and six children) in the children's households.

The attack rate for all cases was 31 of 104 (29.8\%). Twelve confirmed cases (39\%) were asymptomatic, seven were admitted to hospital, and two (the index nursery case and a boy aged 7 years) developed HUS (6.5\%); both recovered. Two cases suffered haemorrhagic colitis while at the nursery; one, a 15 month old girl, was seen by her general practitioner for bloody diarrhoea, but attended the nursery for a further seven days. Figure 1 shows the epidemic curve.

Thirty cases were confirmed by culture. Strains of O157 from cases were phage type 2 (PT2), excreting verocytotoxin type 2 (VT2), and resistant to sulphonamides and tetracycline. VT2 gene subtyping showed that strains from individuals associated with the outbreak carried both VT2 and VT2c sequences. A selection of strains was tested by pulsed field gel electrophoresis and found to be indistinguishable. A further case had HUS and was confirmed by serology. Twenty six of the cases were detected by direct culture. Two additional cases (both asymptomatic) were detected by broth enrichment culture and two cases (also both asymptomatic) were positive only by magnetic bead separation.

\section{ANALYTICAL}

Of 39 girls, 18 were confirmed cases compared with 13 of 65 boys (RR, 2.31; 95\% CI, 1.28 to $4.17 ; \mathrm{p}=0.009)$. This was unaffected by age. Despite the fact that cases would have missed some days as a result of their illness, attendance at the nursery was associated with an increased risk of being a case. Cases attended a median nine days and well children six days (MannWhitney U test, $\mathrm{p}<0.001)$. The first two cases attended the nursery for two days after the onset of their disease on 21 August.

For the 12 cases on the ground floor, the toiletting record showed a mean of 0.51 bowel motions/child/half day session compared with $0.21 /$ child/half day session for the 19 well children. Of the 12 cases, nine had at least one half day session where they would have passed two or more motions compared with six of 19 well 
children (RR, 2.38; 95\% CI, 1.14 to 4.97; $\mathrm{p}<0.05)$. Entries included "offensive", "loose", "watery", and "bloody stool".

A staff member was able to characterise 41 of 104 as part of five groups, made up of varying numbers of children who were friends (two groups of three children, two groups of four children, and one group of 11 older children), as well as a further 16 children who played in pairs. In addition, five were designated as "loners" but played occasionally with the main three groups. The attack rates in the groups of five children and 11 children, respectively, were similar to those observed overall. However, none of the "loners" was a confirmed case. Of the children who played in pairs, in three pairs both friends were confirmed cases; in four pairs both friends were negative; and only one pair was "discordant" (one a confirmed case and one negative). If the status of a child is independent of the pairing, and if the probability of being a case is taken to be seven in 16 , the probability $^{20}$ of observing as few as one pair discordant is 0.038 .

The median child to staff ratio for children $<2$ years old was 3 (range, $2-5$ ), whereas for children $>2$ years old, it was 6 (range, 3-9). On 19 days during the outbreak period, ratios were higher than recommended by the Children's Act Report ${ }^{21}: 3: 1$ for under 2 years and $6: 1$ for older children.

Nearly all children ate meals provided by the nursery each day that they attended. There was no relation between illness and meals eaten.

\section{Discussion}

The source of the original community outbreak of VTECO157 is unknown. Detailed characterisation of the outbreak strain allowed VTECO157 isolates from six other individuals in north Wales over the period to be confidently distinguished from the outbreak. Of the four initial adult cases with the outbreak strain, including the one who lived outside the area, three had histories of purchasing food from a local sandwich bar. However, all subsequent cases could be linked to the day nursery. It was the introduction, presumably by a sick child, of the infection into this setting that transformed a small local outbreak into a major one, with 50 confirmed cases when family and household contacts of nursery cases are included. Wales has had total population surveillance for VTECO157 since $1990,{ }^{22}$ and this outbreak approximately doubled the total cases in Wales in 1995 compared with the almost unvarying numbers observed in other years.

Much emphasis is put on food, particularly beefburgers and cooked meats, as a source of verocytotoxin producing $E$ coli O157. However, person to person spread among young children is also very important. A number of factors indicate person to person spread in this outbreak. First, there was the shape of the outbreak curve. Second, there was a higher attack rate among girls (reflecting the fact that preschool children tend to play in groups of the same sex) and friends who played together. Third, the more frequently a child attended the nursery during this period, the higher was his or her risk of being a case. Fourth, the first two cases attended the nursery for two days after the onset of symptoms.

Why might this outbreak have occurred? Some children attended the nursery for several days while they were ill. For 13 days preceding the onset of illness the recommended child to staff ratio was exceeded, ${ }^{21}$ as a result of school holidays and older children attending at the same time as staff were taking annual holiday. It is tempting to speculate that this may have played a part in compromising the staff's ability to follow hygienic measures aimed at preventing child to child spread.

On 5 September, all children were excluded from the nursery until they had produced two faecal cultures negative for VTECO157 by culture on SMAC and latex agglutination, effectively closing the nursery. To prevent placement of children in other nurseries, parents were contacted by telephone or by letter, in part to remind them of the importance of refraining from doing so. Lists of names were also distributed to health visitors responsible for supervising other child care facilities in the area. This policy, in line with the current UK guidelines $^{2324}$ for the control of person to person transmission, was successful in bringing the outbreak to an end. This suggests that these guidelines are adequate, provided timely detection of index cases occurs. Subsequently, faeces were also tested by enrichment culture and immunomagnetic separation and this accounts for the high (39\%) proportion of asymptomatic cases.

How may such an outbreak be prevented or, at least, contained? The excellent routine record keeping, particularly the toiletting record, was very informative and could, in principle, have enabled the nursery management to anticipate their subsequent problems. This may prove to be a simple to keep early warning system, and should be encouraged in other child care centres. More than one child with more than one bowel motion, particularly if loose or offensive, might trigger more active measures such as inquiring about symptoms in those children at home, suggesting a visit to the family doctor, arranging a faecal sample, and informing and seeking the advice of public health agencies. In this outbreak, such a policy could have led to the problem being identified about 10 days earlier and could have prevented 10-12 confirmed cases. Furthermore, it would help nursery staff to be more assertive in the difficult area of refusing to allow ill children to attend. Children attending while ill contributed to spread in this outbreak.

Nursery facilities are increasingly important economically because, in an increasing number of households, all the potential child carers work. This outbreak raises issues of employment patterns on children's health. ${ }^{25}$ With commercial pressures on both nursery owners and parents, it might be anticipated that ill children will continue to be placed in child care facilities. This may not be in the best interest of children, or ultimately, of the public health. The emergence of VTECO157 disease has 
added a further compelling reason for investigating this issue.

We gratefully acknowledge the contribution of the following members of the outbreak control group: Dr M Adil, Gwynedd members of the outbreak control group: Dr M Adil, Gwynedd Health Authority; Mr E Evans, Aberconwy Borough Council; $\mathrm{Mr}$ C Hardie, Colwyn Borough Council; Mr N Jones, Aberconwy Borough Council; Dr DN Looker, Rhyl Public Health Laboratory; Mrs S Owen, Gwynedd Community Health
Trust; Dr R Roberts, Clwyd Health Authority; Mr A Seed, Wrexham Maelor Borough Council; $\mathrm{Mr} \mathrm{R}$ Sydemham, Aberconwy; Mr P Williams, Rhuddlan Borough Council; and Mrs S Williams, Clwyd Health Authority.

1 Griffin PM, Ostroff SM, Tauxe RV, et al. Illness associated with Escherichia coli O157 infections: a broad clinica spectrum. Ann Intern Med 1988;109:705-12.

2 Boyce TG, Swerdlow DL, Griffin PM. Escherichia coli O157 and the hemolytic-uremic syndrome. N Engl f Med 1995;333:364-8.

3 Griffin PM, Tauxe RV. The epidemiology of infections caused by Escherichia coli O157:H7, other enterohemorrhagic $\mathrm{E}$ coli, and the associated hemolytic uremic syndrome. Epidemiol Rev 1991:13:60-98.

4 Taylor CM, White RHR, Winterborn MH, Rowe B. Haemolytic uraemic syndrome: clinical experience of an outbreak in the West Midlands. BMF 1986;292:1513-16.

5 Martin DL, MacDonald KL, White KE, Soler JT, Martin DL, MacDonald KL, White KE, Soler JT,
Osterholm MT. The epidemiological and clinical aspects of Osterholm MT. The epidemiological and clinical aspects of
the haemolytic uraemic syndrome in Minnesota. $N$ Engl f the haemolytic uraemic

6 Fitzpatrick MM, Shah V, Tromter RS, Dillon MJ, Barrat TM. Long term outcome of childhood haemolytic syndrome. BMF 1991;303:489-92.

7 The Pennington expert group, final report and priority recommendations, Scotland, April 1997. Edinburgh: The Stationery Office.

8 Spika JS, Parsons JE, Nordenberg D, Wells JG, Gunn RA, Blake PA. Hemolytic uremic syndrome associated with Escherichia coli O157.H7 in a day care centre. 7 Pediatr 1986;109:287-91

9 Kohli HS, Chaundhuri AKR, Todd WTA, Mitchell AAB, Liddell KG. The Hartwoodhill hospital E. coli outbreak. Communicable Disease and Envirommental Health Scotland Weekly Report 1993;27:8-11.

10 Morgan D, Newman CP, Hutchinson DN, Walker AM, Rowe B, Majid F. Verotoxin producing Escherichia coli O157 infections associated with the consumption of O157 infections associated with the

11 Lerman Y, Cohen D, Gluck A, Ohad E, Sechter I. A cluster of cases of Escherichia coli O157 infection in a day-care
centre in a communal settlement (Kibutz) in Israel. $\mathcal{F}$ Clin Microbiol 1992;30:520-1.
12 Pickering LK, Bartlett AV, Woodward WE. Acute infectious diarrhoea among children in day care: epidemioloy and diarrhoea among children in day care:

13 Goodman RA, Osterholm MT, Granoff DM, Pickering LK. Infectious diseases and child day care. Paediatrics 1984;74: 134-9.

14 Belongia EA, Osterholm MT, Soler JT, Ammend DA, Braun JE, MacDonald KL. Transmission of Escherichia coli O157:H7 infection in Minnesota child day-care facilities. ҰAMA 1993;269:883-8

15 Van R, Morrow AL, Reves RR, Pickering LK. Environmental contamination in child-care centres. Am 7 Epidemiol 1991:133:460-70.

16 Dean AG, Dean JA, Burton AH, Dicker RC. Epi Info Version 6: a word processing, database, and statistics system for epidemiology on microcomputers. Stone Mountain, Georgia, USA, USD Inc, 1994.

17 Smith HR, Scotland SM. Recent developments in laboratory techniques for the detection of diarrhoeagenic Escherichia coli. Public Health Laboratory Service Microbiology Digest 1994;11:7-17.

18 Cubbon MD, Coia JE, Hanson MF, Thomson-Carter FM. A comparison of immunomagnetic separation, direct culture and polymerase chain reaction for detection of verocytotoxin producing Escherichia coli O157 in human verocytotoxin producing Escherichia col

19 Willshaw GA, Smith HR, Cheasty T, Wall PG, Rowe B. Verocytotoxin producing Escherichia coli O157 outbreaks in England and Wales, 1995: phenotypic methods and genotypic subtyping. Emerg Infect Dis 1997;3:561-5.

20 Kirkwood BR. Binomial probability. Essentials of medical statistics. Oxford: Blackwell Scientific Publications, 1992.

21 Children Act Report. A report by the Secretaries of State for Health and for Wales on the Children Act 1989 in pursuance of their duties under section 83 (6) of the act. London: HMSO, their d
1992.

22 Salmon RL, Smith RMM. How common is Escherichia coli 0157 and where is it coming from? Total population surveillance in Wales 1990-1993. Recent advances in verocytotoxin-producing Escherichia coli infections. Amsterdam: Elsevier 1994:73-75.

23 PHLS working group on verocytotoxin producing Escherichia coli. Interim guidelines for the control of infections with verocytotoxin producing Escherichia coli (VTECO157). Commun Dis Rep CDR Suppl 1995;5:R77-

24 PHLS Salmonella Committee. The prevention of human transmission of gastrointestinal infections, infestations and bacterial intoxications. Commun Dis Rep CDR Suppl 1995; 5:R164.

25 Holmes SJ, Marrow AL, Pickering LK. Child-care practices: effect of social change on the epidemiology of infectious diseases and antibiotic resistance. Epidemiol Rev 1996:18;10-28 